\title{
Trabalhonecessário
}

ISSN: 1808 - 799X

ANO 12, № 19 - 2014

\section{O PENSAMENTO DE E.P. THOMPSON E A "EXPERIÊNCIA" COMO MEDIAÇÃO NECESSÁRIA NA EDUCAÇÃO DE JOVENS E ADULTOS TRABALHADORES EM ITABORAÍ/RJ}

RESUMO:

Henrique dos Santos Pacheco ${ }^{1}$

A dialética necessária entre educação e experiência, construída por Thompson em sua prática na educação de adultos trabalhadores, parte do pressuposto de que aquilo que as pessoas comuns fazem é digno de interesse e atenção. Sob o ponto de vista da educação de classe, a EJA trabalhadores preconiza que, na produção social de sua existência, os seres humanos criam seus próprios valores, sua cultura própria, intrínsecos ao seu modo de vida. Dessa forma, torna-se necessária a resistência às determinações do mercado e à pedagogia política do capital para que as experiências de classe sejam socializadas e para que o público da EJA seja conhecedor de sua própria cultura, como sujeitos históricos reconhecidos entre si. Em tempos de crise do capital e do trabalho assalariado, percebemos na educação pública a influência cada vez maior das ideias que procuram a valorização do capital humano, fazendo das escolas uma extensão do processo produtivo, da cultura hegemônica, de uma pedagogia política do capital. Desta forma, a EJA trabalhadores configura-se em um mecanismo de mediação da luta de classes, um campo de disputa entre o capital e o trabalho.

PALAVRAS-CHAVE: educação de jovens e adultos; experiência; mundo do trabalho

ABSTRACT: The necessary dialectic between education and experience, built by Thompson in his practice in workers education, assumes that what ordinary people do is worthy of interest and attention. From the point of view of class education, young and adult education defends that workers create their own values, their own culture, intrinsic to their way of life in the social production of their existence, humans. Thus, it becomes necessary resistance to determinations of market and political pedagogy of capital so that the class experiences are socialized and the public of the EJA is knowledgeable of their own culture, as historical subjects recognized each other. In times of capital and wage labor crisis

\footnotetext{
${ }^{1}$ Mestrando do programa de pós-graduação em Educação na Universidade Federal Fluminense (UFF), campo de confluência "Trabalho e Educação", sob orientação da prof. Sonia Maria Rummert. Professor de História da Rede Estadual e do município de Itaboraí, atuando, neste último, na coordenação da Educação de Jovens e Adultos.
} 


\section{Trabalhonecessário}

ISSN: 1808 - 799X

ANO 12, № 19 - 2014

in public education perceive the increasing influence of the ideas seeking the enhancement of human capital, making the school an extension of the production process, the hegemonic culture, a political pedagogy of capital. Thus, the EJA workers set up a mechanism for mediation of class struggle, a field of struggle between capital and work.

KEY-WORDS: young and adult education; experience; world of work

\section{Introdução}

Partindo de uma history from bellow, o pensamento thompsoniano rompe com reducionismo econômico que era submetida a tradição marxista em meados do século XX. Muito influenciado pela metáfora base/superestrutura, pelo dogmatismo do pensamento stalinista e pelo pensamento de Althusser, o debate no interior da academia e do Partido Comunista da Grã-Bretanha rechaçava fontes significativas para a compreensão da sociedade, como aquela do século XVIII que resistia ativamente aos efeitos do avanço da Revolução Industrial, na medida em que lutavam para a manutenção dos seus costumes, do seu padrão de vida, ameaçados pelo avanço das forças produtivas e da divisão do trabalho. Nesse sentido, a formação de uma New Left proporcionará a recuperação da historicidade no interior do materialismo histórico, à luz das categorias "experiência", "cultura" e "formação", no intuito de constituir uma alternativa às limitações encontradas nas interpretações estruturalista e funcionalista, comuns da história econômica e da sociologia. Portanto, a história social da cultura e do trabalho fornece os mecanismos indispensáveis a uma história social da educação, principalmente quando o objeto de estudo é o ensino de história na educação de jovens e adultos (EJA) trabalhadores. 


\title{
Trabalhonecessário
}

ISSN: 1808 - 799X

ANO 12, № 19 - 2014

A despeito dos tradicionalismos acadêmicos, o convívio com os testemunhos vivos e a utilização das fontes orais do tempo presente proporciona à historiografia e ao ensino de história um complexo conjunto de fontes, as quais são somadas às tradicionais fontes escritas. Inclusive, devido ao fato da pesquisa em questão desenvolver uma análise dos primeiros anos do século XXI (20012013), ratificamos a necessidade da amplitude das fontes a serem pesquisadas:

\begin{abstract}
Em primeiro lugar, a emergência da história do século XX com um novo estatuto, definido por alguns como a história do tempo presente, portanto portadora da singularidade de conviver com testemunhos vivos que sob certo aspecto condicionam 0 trabalho do historiador, coloca obrigatoriamente em foco os depoimentos orais. Além disso, as próprias transformações das sociedades modernas e as conseqüentes mudanças no conteúdo dos arquivos, que cada vez mais passam a dispor de registros sonoros, impulsionam a tendência a uma revisão do papel das fontes escritas e orais. (FERREIRA, Marieta de Moraes, 2002, p. 324).
\end{abstract}

Tendo em vista a distinção entre memória e história, citamos as colaborações de Pierre Nora, Maurice Halbwachs e Patrick Hutton, analisadas por Marieta de Moraes Ferreira em "História, tempo presente e história oral" (2002):

\begin{abstract}
A história busca produzir um conhecimento racional, uma análise crítica através de uma exposição lógica dos acontecimentos e vidas do passado. A memória é também uma construção do passado, mas pautada em emoções e vivências; ela é flexível, e os eventos são lembrados à luz da experiência subseqüente e das necessidades do presente. (FERREIRA, 2002, p. 321).
\end{abstract}

Conforme Maurice Halbwachs, a memória envolve uma relação entre a repetição e a rememoração, ressaltando que a revisão das memórias ocorre juntamente com a sua repetição. Para Patrick Hutton, a memória coletiva depende do poder social do grupo que a detém, porque, na rememoração, nós não lembramos as imagens do passado como elas aconteceram, e sim de acordo com as forças sociais do presente que estão agindo sobre nós (HUTTON, 1993). Portanto, há que se contestar a transmutação de qualquer professor, e inclusive o 


\section{Trabalhonecessário}

ISSN: 1808 - 799X

ANO 12, № 19 - 2014

de história, em mero reprodutor de uma pedagogia política do capital, bancária e acrítica.

Analisar o ensino de história na educação de jovens e adultos trabalhadores em um contexto de avanço do capital envolve uma série de questões, principalmente aquelas voltadas ao currículo, à prática docente e às condições de trabalho nas escolas. Levando-se em conta a precarização do trabalho docente nas escolas públicas e a forma pela qual a EJA configura-se hoje num mecanismo de mediação do conflito de classes e manutenção de hegemonia, acreditamos que a elaboração e a prática de um currículo voltado aos interesses da classe trabalhadora produzam os efeitos necessários para que ações contra hegemônicas em EJA ganhem vitalidade, no intuito de afastar cada vez mais as influências dos ditames do modo de produção capitalista na educação pública. Para Neves e Martins:

\footnotetext{
Qualquer classe social precisa de um arcabouço de ideias, valores e normas bem articulados para promover o consenso e construir a hegemonia. De acordo com Gramsci, as formas de dominação se efetivam não apenas por ações econômicas e políticas de modo coercitivo; o consenso construído por mecanismos ideológicos é imprescindível para a classe dominante, pois, com esses movimentos, ela apresenta seu projeto de sociedade e sua visão de mundo como se fossem verdadeiros e universais. (MARTINS, NEVES, 2013, p. 344).
}

Levando em consideração que a história é a ciência do contexto, do processo e do movimento (THOMPSON, 2001, p. 243), refutamos qualquer análise que iguala "base" a "formação social", pois esta vai muito além da economia. Inclusive, as leis, a cultura e a arte estão em contato direto com as relações sociais de produção, compondo um único bloco histórico, não caracterizando categorias estáticas e simplesmente determinadas pelo modo de produção. Muito pelo contrário, o signo "formação" é composto por uma série de fatores que merecem a atenção do historiador, no que diz respeito à ideia de processo e movimento, tendo nos estudos da cultura e da experiência a verossi- 


\section{Trabalhonecessário}

ISSN: 1808 - 799X

ANO 12, № 19 - 2014

milhança necessária à produção do conhecimento histórico.

Segundo Angela Martins e Lucia Neves, ao se insurgirem contra as concepções dominantes do materialismo histórico à época, Antonio Gramsci, Edward Thompson e Raymond Williams retomaram as críticas de Marx e Engels às ideias materialistas do século XIX "que separavam os objetos dos sujeitos e desconsideravam a ação subjetiva, questionando a tradição estruturalista e atribuindo novos significados para a compreensão do ser e da dinâmica social na contemporaneidade". (MARTINS \& NEVES, 2013, p. 343). Dessa forma, ao contrário da concepção do economicismo vulgar, o materialismo humanista nega uma relação determinação, em favor de uma reciprocidade dialética entre infra e superestrutura.

Ao considerarmos que o processo de construção do conhecimento na EJA requer o diálogo como pressuposto para o reconhecimento entre os sujeitos históricos envolvidos neste processo, o "materialismo humanista" ou o "humanismo socialista" de Thompson ressalta que "a análise da experiência, gerada na vida material, contribui para o entendimento das diversas formas de organização da vida social e do sentido histórico da vida dos trabalhadores". (VEDRAMINI, TIRIBA, 2011, p. 1). Tendo em vista a vida material desses sujeitos e suas experiências de vida, a construção do conhecimento mantém uma relação direta com a forma pela qual interpretam o mundo. Suas experiências vividas, percebidas e modificadas são fontes históricas para a análise de sua formação. Para Thompson,

A experiência é um termo médio necessário entre o ser social e a consciência social: é a experiência (muitas vezes a experiência de classe) que dá cor à cultura, aos valores e ao pensamento: é por meio da experiência que 0 modo de produção exerce uma pressão determinante sobre outras atividades: e é pela prática que a produção é mantida. (THOMPSON, 1981, p. 112). 


\section{Trabalhonecessário}

ISSN: 1808 - 799X

ANO 12, № $19-2014$

Conforme Thompson, em "A miséria da teoria", a "experiência foi, em última instância, gerada na vida material, foi estruturada em termos de classe, e consequentemente o ser social determinou a consciência social. (THOMPSON, 1981, p. 189). O conceito de "experiência", portanto, informa que as "estruturas objetivas" geram efeitos sobre as vidas das pessoas, no momento em que a consciência social é determinada pelo ser social, sendo tarefa dos cientistas a investigação sobre o quê essas "estruturas" fazem às vidas das pessoas, e como elas reagem. Inclusive, a colaboração de E. P. Thompson e Raymond Williams no quadro teórico da pesquisa torna-se indispensável, tendo em vista as suas experiências na educação de adultos na Inglaterra entre os anos 1940 e 1960, as quais colaboraram na construção de suas obras.

Tendo em vista que o seu grande público faz parte da população economicamente ativa, a EJA assume características bem peculiares, as quais interferem no processo pedagógico e na construção do conhecimento, por meio dos caminhos pelos quais o professor medeia as relações epistêmicas no âmbito escolar. Desse modo, caracterizada em uma educação de classe, na qual trabalhadores educam trabalhadores, a EJA se configura hoje em um campo de disputa e de manutenção de hegemonia. A vinculação dessa modalidade de ensino ao mundo do trabalho deve concebê-lo "não como reprodução do capital, mas como reprodução ampliada da vida" (VENDRAMINI, TIRIBA, 2011, p. 2).

Ainda relacionada aos cursos supletivos, às antigas campanhas nacionais de alfabetização e à simples correção de fluxo, a EJA também luta para que seja reconhecida em suas especificidades - as quais transcendem a escolarização e a simples lógica do resumo dos conteúdos do ensino regular fundamental e médio. Logo, esta pesquisa é desenvolvida tendo em vista os sentidos histórico e ontoló- 


\title{
Trabalhonecessário
}

ISSN: 1808 - 799X

ANO 12, № 19 - 2014

gico da relação trabalho x educação, preconizando a formação humana, omnilateral, e para a vida social. Conforme Jaqueline Ventura,

\begin{abstract}
É perceptível em sua trajetória histórica, que a EJA sempre foi tratada pelo Estado como uma educação de segunda classe, que nunca assegurou 0 acesso e a permanência na escola, nem as condições de acesso ao conhecimento científico e tecnológico (...) a EJA praticada hoje, pelo Estado brasileiro, constitui-se em um novo mecanismo de mediação do conflito de classes; apoiada nas noções de empregabilidade, de competências e de empoderamento, difunde entre os trabalhadores a ética individualista e competitiva dos homens de negócios. (VENTURA, 2011, p. 93).
\end{abstract}

Nesse aspecto, o processo de eliminação da história social da classe trabalhadora é condição sine qua non para que as suas experiências de luta principalmente, as de classe - não sejam socializadas ao grande público. Seguindo uma concepção dialética da história (GRAMSCI, 1987), como ciência e como componente curricular, devemos lutar contra o processo de eliminação da história social do trabalho, $\mathrm{o}$ qual se materializa constantemente $\mathrm{e}$ processualmente na periferia do capital, tendo em vista o reconhecimento da escola como instituição historicamente associada à organização da cultura.

Analisar a educação de jovens e adultos trabalhadores inseridos em uma conjuntura econômica que tem como sustentáculo a proliferação das desigualdades sociais é o fio condutor da pesquisa. Tratando da EJA na perspectiva da educação de classe, pretendo abordar as questões voltadas à construção e à efetivação de um currículo crítico de história junto aos jovens e aos adultos trabalhadores da Escola Municipal Genesio da Costa Cotrim, assim como as influências da educação popular nas partes constitutivas desta totalidade articulada. Tendo o materialismo histórico como metodologia de trabalho, analisarse-á as particularidades deste município fluminense, com vistas à aproximação da realidade - tendo a história como mediação - até chegarmos ao todo concreto como síntese de múltiplas determinações, as quais têm atuado no sentido de pre- 


\title{
Trabalhonecessário
}

ISSN: 1808 - 799X

ANO 12, № 19 - 2014

servar a subsunção do trabalho ao modo de produção capitalista numa sociedade de classes.

\section{Por um ensino de História em diálogo com as experiências dos alunos}

Ao nos debruçarmos sobre a EJA e sobre suas possibilidades epistemológicas, afirmamos que "as pessoas aprendem com e através da experiência" (CANARIO, 2000). Deriva daí um pressuposto essencial na educação dos jovens e adultos "segundo o qual o patrimônio experiencial de cada um representa o recurso mais importante para a realização de novas aprendizagens". No que concerne à pesquisa em EJA e na introdução da categoria "experiência", Edward Palmer Thompson é indispensável à nossa análise:

\begin{abstract}
O que é diferente acerca do estudante adulto é a experiência que ele traz para a relação. A experiência modifica, às vezes de maneira sutil $\mathrm{e}$ às vezes mais radicalmente, todo o processo educacional; influencia os métodos de ensino, a seleção e o aperfeiçoamento dos mestres e o currículo, podendo até mesmo revelar pontos fracos ou omissões nas disciplinas acadêmicas tradicionais e levar à elaboração de novas áreas de estudo. (THOMPSON, 2002, p. 13).
\end{abstract}

A educação de jovens e adultos na rede municipal de Itaboraí/RJ ${ }^{2}$ vem passando por um processo de reformulação de seu referencial curricular - o qual se encontra em permanente construção - no sentido de ampliar as frentes de efetivos diálogos junto aos alunos. Trabalhando nessa perspectiva, podemos mencionar o atual contexto sócio-econômico do município: o início das obras de instalação do COMPERJ ${ }^{3}$ e de inúmeras empresas prestadoras de serviços técni-

\footnotetext{
${ }^{2}$ Município da região metropolitana do Rio de Janeiro, fundado em 16 de agosto de 1696, com uma população de, aproximadamente, 218.090 habitantes (Censo IBGE/ 2010).

3 "Um projeto de 15 bilhões de dólares", capa da revista "Visão do Conleste" (Consórcio Intermunicipal de Desenvolvimento do Leste Fluminense).
} 


\section{Trabalhonecessário}

ISSN: 1808 - 799X

ANO 12, № 19 - 2014

cos especializados nas áreas de engenharia, hotelaria, alimentação, financeira etc. Paralelamente à chegada desses investimentos, cabe-nos citar o intenso fluxo migratório ${ }^{4}$ à região, fruto do aumento expressivo do número de empregos gerados direta e indiretamente, assim como a ampla utilização dos contratos temporários de trabalho nas obras de construção do parque industrial. Neste processo de reformulação curricular da educação de jovens e adultos trabalhadores em tempos de avanço das forças produtivas na região, citamos Ciavatta \& Rummert:

Compreendo o currículo também como uma totalidade articulada, construída e em construção. Podemos concebê-lo como locus fecundo de explicitação das relações entre totalidade e particularidade inerentes a todo o conhecimento. Trata-se, portanto, de conceber o currículo como movimento dialético em que a totalidade e particularidade se completam e colocam, permanentemente, novos desafios aos processos de produção e apropriação do conhecimento. (CIAVATTA \& RUMMERT, 2010, p. 470).

O ensino de História ${ }^{5}$ assume papel fundamental neste processo, uma vez que o "trabalho" e inúmeros outros temas de relevância social e cultural são claramente discutidos em sala de aula, a saber: cidadania; relações de poder; economia; mídia; saúde, etc. Ou seja, o estudo da "ação do homem no tempo 6" enquanto propósito da disciplina - possui na EJA um aspecto singular, a ser associado ao mundo da classe trabalhadora (alunos/professores/comunidade escolar), na perspectiva de uma educação crítica e em consonância com os princípios da educação popular.

O autor em questão possui uma relação peculiar com o objeto da pesquisa em questão. Para além de suas contribuições para a história social e para a crítica da tradição marxista, E. P. Thompson constituiu seu pensamento com base

\footnotetext{
${ }^{4}$ A população da cidade vem crescendo significativamente. Analisando Censos anteriores, por exemplo, em 2000, possuía um total de 162.742 habitantes. (Censo IBGE/1991).

${ }^{5}$ Sobre o assunto, ver "Ensino de História: fundamentos e métodos" (BITTENCOURT, 2009).

${ }^{6}$ Conceito presente na obra "Apologia da História ou O Ofício de Historiador" (BLOCH, 2001).
} 


\section{Trabalhonecessário}

ISSN: 1808 - 799X

ANO 12, № 19 - 2014

na participação ativa na militância política no partido comunista, na luta na II Guerra Mundial, nos movimentos sociais e, sobretudo, na educação de adultos trabalhadores. Lecionando literatura inglesa e história para esse público entre os anos de 1948 e 1965 no projeto "extramuros" da Universidade de Leeds,

Thompson entrou em sintonia com um público que o possibilitou, como historiador e professor, a apreensão da totalidade social mediada pela experiência e pela cultura popular. Nas salas de aula, segundo Fortes, Negro e Fontes (2001):

Thompson encontrava interlocução e estímulo, classes frequentadas por homens e mulheres comuns (trabalhadores manuais, bancários, funcionários de escritório, profissionais da seguridade social e professores da rede de ensino não-universitária). (FORTES, NEGRO \& FONTES, 2001, p. 24).

O conceito de "experiência" foi a "chave mestra" para que ele, em $A$ formação da classe operária inglesa (1963) expusesse a sua definição de

"classe", conceito central no materialismo histórico. Marcelo Badaró traz essa informação à tona quando cita Dorothy Thompson, num comentário sobre a influência da prática docente na constituição do pensamento do professor/historiador, dez anos após a publicação da obra em referência:

O livro era baseado no tipo de docência que Edward exercitou por dez anos. É o tipo de docência que fizemos o tempo todo. O que eu acho que produziu um tal avanço, e fez as pessoas verem o livro como tão revelador, foi que ele partia da perspectiva de que o que as pessoas comuns fazem é digno de interesse e atenção. Hoje isso é tão amplamente aceito que não é visto como revolucionário. Isso é basicamente uma questão fortemente política de fato. (THOMPSON, D., 2000, p. 8 apud MATTOS, 2012, p. 29).

Logo, podemos inferir que a ligação entre a experiência de vida dos trabalhadores e as manifestações de sua consciência de classe era um elemento presente na forma como Thompson entendia seu trabalho docente, junto a um público que lhe era negado o acesso integral ao ensino superior, numa sociedade 


\section{Trabalhonecessário}

ISSN: 1808 - 799X

ANO 12, № 19 - 2014

do pós-guerra de "reconstrução", que demandava cada vez mais a sua força de trabalho e a separação entre o trabalho manual e o trabalho intelectual.

$\mathrm{Na}$ prática docente na educação de adultos, Thompson acreditava aprender tão quanto seus alunos aprendiam, "negando uma audiência passiva, combinando diversos talentos e fundindo diferentes conhecimentos e experiências para um fim comum". (MATTOS, 2012, p. 30). Assim como Edward, Raymond Williams e Richard Hoggart - intelectuais que também aprofundaram os estudos culturais no materialismo histórico - julgaram suas trajetórias como professores de adultos na Workers Educacional Association (WEA) como fundamentais na formulação de suas teorias. A militância educacional fez com que esses autores contestassem tanto as teses liberais - por meio da explicação que as posições de classe são estabelecidas a partir da produção, e não do consumo - quanto as teses economicistas, as quais utilizavam os cálculos matemáticos na mensuração do padrão de vida e da classe, ignorando os próprios valores, costumes e tradição da classe trabalhadora.

De acordo com Marcelo Badaró, em E. P. Thompson e a crítica ativa do materialismo histórico, "o respeito à experiência dos trabalhadores, aliás, é uma chave fundamental para entendermos de que forma a atividade de Thompson como professor de literatura inglesa e história foi um elemento fundamental de seu aprendizado prévio à redação de $A$ formação" (MATTOS, 2012, p. 30). Relacionando sua prática docente à pesquisa historiográfica, discorre Mattos:

A partir de debates como os desse grupo e de sua experiência na militância política e na educação de jovens e adultos de origem operária, E. P. Thompson compôs, com seu $A$ formação da classe operária, um estudo que, pela ênfase na dimensão cultural da classe e pela riqueza de uma análise que reconstituía importantes aspectos da vida comunitária dos trabalhadores "pré-industriais", pode ser lido a partir de vários paralelos com outros trabalhos, como o estudo de Hoggart e a produção de Raymond Williams. (MATTOS, 2012, p. 24). 


\title{
Trabalhonecessário
}

ISSN: 1808 - 799X

ANO 12, № 19 - 2014

Logo, destacamos a forma pela qual o historiador inglês utilizou a fusão entre as diversas experiências de seus alunos como mediação necessária para explicar a formação da classe operária inglesa, haja vista sua trajetória na prática docente em educação de adultos trabalhadores. Indubitavelmente, percebemos a indissociabilidade entre o professor e o pesquisador.

Badaró vai além, e nos mostra a recuperação dos relatórios de Thompson como "tutor" dos cursos do Departamento de Educação Extramuros da

Universidade de Leeds, feito por Peter Searby (1993), nos quais Thompson acredita "ter aprendido mais do que transmitido" (MATTOS, 2012, p. 30). Analisando os relatórios de Thompson, diz o historiador:

\begin{abstract}
Os depoimentos de seus ex-alunos são ricos em elogios à forma como Thompson os cativava em seus cursos, estimulando-os à leitura e à participação em classe por meio de uma ênfase em apresentá-los ao conteúdo histórico e literário como algo que Ihes pertencia e fazê-los perceberem como parte ativa da história que aprendiam tanto quanto faziam. (MATTOS, 2012, p. 31).
\end{abstract}

Tendo em vista a aproximação entre a prática docente de Thompson na educação de adultos trabalhadores e a concepção de EJA como formação humana omnilateral, na qual os alunos e professores envolvidos no processo educacional são sujeitos ativos no processo histórico, citamos um fragmento da entrevista à Dorothy Thompson (2000), presente em MATTOS (2012), na qual a esposa do historiador inglês recupera o depoimento de um de seus alunos (Peter Thorton) do curso de Leeds:

As aulas de Edward Thompson (...) tinham esse efeito de fazer com que você percebesse que a história não era algo separado e à parte; ela era uma progressão da qual você faz parte. Eu sempre sentia isso. E quando ele tratava de coisas como os tecelões manuais de Yorkshire, os ludistas, o desenvolvimento social da revolução industrial nesta parte do mundo, você muito rapidamente percebia o quanto você e a sua gente 


\section{Trabalhonecessário}

ISSN: 1808 - 799X

ANO 12, № 19 - 2014

eram parte daquilo. (THOMPSON, D., 2000, p. 17 apud MATTOS, 2012, p. 31).

\section{A "cultura" e a crítica ativa do materialismo histórico}

$\mathrm{Na}$ compreensão das formações sociais contemporâneas, torna-se necessário o estudo da cultura, pois ela é fundamental para a consolidação da vida material e de um projeto societário. Ela possui um papel preponderante para compreendermos os mecanismos de manutenção de hegemonia, e pela educação a cultura é instituída. Em tempos de crise do capital e do trabalho assalariado, percebemos na educação pública a influência cada vez maior das ideias que procuram a valorização do capital humano, fazendo das escolas uma extensão do processo produtivo, da cultura hegemônica, de uma pedagogia política do capital.

Concebendo a cultura de uma forma bem distinta daquela referenciada tanto pelo liberalismo clássico quanto pelo marxismo ortodoxo, não há como dissociá-la dos processos materiais de produção da vida, cujo ser e consciência formam uma totalidade histórica. Sendo assim, o materialismo cultural presente na obra de Raymond Williams é adequado quando enxergamos a educação de jovens e adultos trabalhadores sob a perspectiva da educação de classe e da escola como organizadora da cultura. A cultura e a experiência dos subalternos, uma vez socializada ao público, vão na contramão dos processos de eliminação da história social da classe trabalhadora e da educação atrelada ao mundo do trabalho alienado. O materialismo cultural pressupõe a cultura como ordinária, comum e potencialmente transformadora. Desse modo, como defende Thompson, a análise dos costumes, das normas e do modo de vida das sociedades no tocante a resistência às mazelas impostas pelo avanço das forças produtivas é um ponto crucial para termos uma produção historiográfica feita a partir da ótica 


\section{Trabalhonecessário}

ISSN: 1808 - 799X

ANO 12, № $19-2014$

dos subalternos.

A despeito dos estudos culturais possuírem hoje, na história social da cultura, o seu reconhecimento teórico-metodológico, eles ainda sofrem críticas e comparações descabidas por parte dos resquícios deixados pelo establishment do marxismo ortodoxo, conforme elucida Vendramini e Tiriba:

\footnotetext{
Por dedicar-se ao estudo das tradições, dos costumes e modos de vida, Thompson tem sido interpretado, de forma equivocada, como um historiador culturalista. Entretanto, ao contrário de compreender a cultura no seu sentido abstrato, descolada da materialidade histórica, o autor privilegia o estudo empírico, atenta-se para os sujeitos que vivenciam os processos culturais, articulando-os com o movimento real da sociedade, sem perder de vista a análise mais ampla de base marxista. (VENDRAMINI, TIRIBA, 2011, p. 5).
}

Logo, ampliar o conceito de cultura é imprescindível para a apreensão da totalidade social, já que ela é intrínseca aos pressupostos ontológicos do homem na produção de sua existência, ao lado da educação e do trabalho.

Nesse aspecto, Thompson critica o reducionismo do termo "sociedade préindustrial", como se a sociedade inglesa do século XVIII tivesse sua história eliminada gradativamente, em consonância ao avanço da industrialização. Sob a perspectiva da história social da cultura e do trabalho, Thompson alegou estar "cada vez mais disposto à utilização de material folclórico" (THOMPSON, 2001, p. 227) - outrora ignorado pelos historiadores, sociólogos e economistas corroborando a cultura como ordinária e dialogando com a antropologia social. 0 "eclipse" da consciência plebéia e da "economia moral das multidões" chega ao fim quando esse historiador reúne um acervo complexo que manifesta uma verdadeira luta de classes na Inglaterra do século XVIII, antes mesmo da formação da mesma. 


\section{Trabalhonecessário}

ISSN: 1808 - 799X

ANO 12, № 19 - 2014

Em Folclore, Antropologia e História Social, Thompson evidencia a historicidade do ser humano no diálogo com a antropologia social, mostrando a miséria da teoria do chamado "marxismo ortodoxo e vulgar", que não considera os rituais, as práticas costumeiras e consuetudinárias e as diversas formas de protestos populares, como os motins de fome do século XVIII naquele país. Sobre o significado simbólico das formas de protesto popular, alega que "os historiadores da tradição marxista influenciados pelo conceito gramsciano de hegemonia também têm investigado com novos olhos as formas de dominação e controle da classe dominante" (THOMPSON, 2001, p. 239). Encontramos, inclusive, mais uma aproximação entre esses pensadores, no que diz respeito ao conceito de Estado ampliado (hegemonia couraçada de coerção) e a comparação da sociedade inglesa do século XVIII como um "teatro do poder", sugerindo que o controle ou a dominação podem se revestir de uma "roupagem teatral".

Mencionando o estado como possuidor dos mecanismos de coerção e de monopólio da violência, Thompson afirma que a Praça de Tyburn - local das execuções em Londres setecentista - constituía-se num verdadeiro palco para o "teatro" do controle de classes:

\footnotetext{
Em todas as sociedades, naturalmente, há um duplo componente essencial: o controle político e o protesto, ou mesmo, a rebelião. Os donos do poder representam seu teatro de majestade, superstição, poder, riqueza e justiça sublime. Os pobres encenam seu contrateatro, ocupando o cenário das ruas dos mercados e empregando o simbolismo do protesto e do ridículo. (THOMPSON, 2011, p. 240)
}

Seja pela análise das fontes que denunciam as injustiças sociais, os protestos populares, a rough music e as diversas formas simbólicas de resistência da população à opressão, Thompson afirma que "assim como a história econômica pressupõe a disciplina da economia, a história social deve pressupor a disciplina da antropologia social" (THOMPSON, 2001, p. 251). Contudo, constituise em um erro a transposição de conclusões da pesquisa antropológica para a 


\title{
Trabalhonecessário
}

ISSN: 1808 - 799X

ANO 12, № 19 - 2014

história caso um ritual seja analisado de forma isolada, sem um nexo junto ao contexto das relações sociais. Esclarecendo a insuficiência teórica presente no marxismo ortodoxo referente à análise da cultura, argumenta o historiador:

\begin{abstract}
A analogia base e superestrutura é radicalmente inadequada. Não tem conserto. Está dotada de uma inerente tendência ao reducionismo ou ao determinismo econômico vulgar, classificando atividades e atributos humanos ao dispor alguns destes na superestrutura (lei, arte, religião, "moralidade"), outros na base (tecnologia, economia, as ciências aplicadas), e deixando outros ainda a flanar, desgraçadamente, no meio (lingüística, disciplina de trabalho). (THOMPSON, 2001, p. 256).
\end{abstract}

Dessa forma, não há como quantificar a violência, a resistência, os protestos e os costumes em números, sem conhecer o âmago das questões que engendram a luta de classes. A partir da introdução do termo ausente "experiência" e da utilização de fontes outrora rechaçadas, a history from bellow materializa-se como possibilidade de aproximação da verdade: "a velha noção utilitária de que todos os fatos são quantificáveis e mensuráveis e de que tudo o que não pode ser medido não é um fato, está viva e animada, e domina uma grande parte da tradição marxista" (THOMPSON, 1981, p. 193-194).

Thompson em A miséria da teoria evidencia alguns campos de confluência científica: os "termos de junção se situam no ponto de junção entre disciplinas analíticas (como necessidade em economia, que pode ser vista como uma norma em antropologia) ou entre estrutura e processo (como classe e modo de produção)" (THOMPSON, 1981, p. 125). Dessa forma, "experiência" e "cultura" estão em um ponto de junção, pois as pessoas não experimentam sua própria experiência apenas como ideias e no âmbito do pensamento, como sugerem os idealistas. Além dos pontos de junção, Thompson menciona os "conceitos de junção", tais como "necessidade", "classe" e "determinação", que pela "experiência" torna a estrutura estática em processo, reinserindo o sujeito na história. Isso envolve o estudo de sistemas densos e excluídos até então pelo marxismo, tais como: parentesco, costumes, as regras visíveis e invisíveis da re- 


\section{Trabalhonecessário}

ISSN: 1808 - 799X

ANO 12, № 19 - 2014

gulação social, hegemonia e deferência, formas simbólicas de dominação e de resistência, fé religiosa e impulsos milenaristas, maneiras, leis, instituições e ideologias" (THOMPSON, 1981, p. 189).

Mencionando a categoria "experiência" e os "silêncios de Marx" (THOMPSON, 1981), o historiador inglês critica a negligência ao caráter genético da teoria de Marx, no seu sentido evolutivo. Critica também que "a busca por uma teoria perfeita, totalizada, é a heresia original contra o conhecimento, pois os homens se aprisionam em estruturas de sua própria criação porque mistificam a si mesmos" (THOMPSON, 1981, p. 183). Inclusive, em ataque a Althusser, na mesma obra, afirma que o conceito antropológico de "cultura" seria deplorado por ele, em resistência à evolução dos métodos na pesquisa histórica. Sobre os "silêncios de Marx":

O que resta fazer é interrogar os silêncios reais, através do diálogo do conhecimento. $E$, à medida que esses silêncios são penetrados, não cosemos apenas um conceito novo ao pano velho, mas vemos ser necessário reordenar todo o conjunto de conceitos. Não há nenhum altar mais oculto que seja sacrossanto de modo e obstar a indagação e a revisão. (THOMPSON, 1981, p. 185).

Para conferir ainda mais rigor teórico e afastar qualquer crítica da intelligentsia ou do establishment, a riqueza literal das fontes que legitimam o ofício do historiador que dialoga com o materialismo humanista e cultural é a base sólida na qual se estrutura o trabalho daqueles que estudam a agência humana no tempo. Tal constructo teórico possibilitou à historiografia reinterpretar o conceito de "classe":

Classe não é, como gostariam alguns sociólogos, uma categoria estática: tais e tais pessoas situadas nesta e naquela relação com os meios de produção, mensuráveis em termos positivistas ou quantitativos. Classe, na tradição marxista, é (ou deve ser) uma categoria estática descritiva de pessoas numa relação no decurso do tempo e das maneiras pelas quais se tornam conscientes de suas relações, como se 


\title{
Trabalhonecessário
}

ISSN: 1808 - 799X

ANO 12, № 19 - 2014

\begin{abstract}
separam, unem, entram em conflito, formam instituições e transmitem valores de modo classista. Neste sentido, classe é uma formação tão "econômica" quanto "cultural"; é impossível favorecer um aspecto em detrimento do outro, atribuindo-se uma prioridade teórica. (THOMPSON, 2001, p. 260).
\end{abstract}

Analisando o processo da formação de classe e das particularidades envolvidas tanto nas pesquisas de Thompson e Williams, esses autores são bem claros quando alegam que cada espaço/tempo possui suas especificidades.

Portanto, de modo algum as experiências inglesas devem ser apropriadas como modelos explicativos funcionais, são aqueles com os quais os autores tiveram contato e Ihes possibilitaram uma problematização pertinente, como argumentam Vendramini e Tiriba:

\begin{abstract}
Por entender que classe é uma formação tanto cultural quanto econômica, Thompson adverte que não devemos fazer generalizações a partir da experiência inglesa. Isso significa que a compreensão da formação da classe operária na Irlanda, na Escócia ou em qualquer outro país ou nação requer uma reconstrução histórica que considere as particularidades de cada espaço/tempo, como as formas como se materializam no tecido social as questões de religiosidade, dos laços sindicais, da cultura popular, da composição do campesinato etc. Em outras palavras, sem desconsiderar as determinações gerais do modo de produção capitalista, cabe ao pesquisador perceber as formas peculiares como os sujeitos sociais participam, de forma ativa, nos processos de produção da existência. (VENDRAMINI, TIRIBA, 2011, p. 9).
\end{abstract}

\section{Considerações Finais}

Tanto no materialismo humanista de Thompson, quanto no materialismo cultural de Williams, as contribuições de Gramsci foram fundamentais para que essas teorias fossem construídas. Sob uma concepção dialética da história, o homem é um devir, sujeito a contínuas transformações e constituído nas relações de classe. Desse modo, o pensador italiano forneceu as bases para que os marxistas ingleses contestassem o stalinismo e o reducionismo econômico, sob a 


\section{Trabalhonecessário}

ISSN: 1808 - 799X

ANO 12, № 19 - 2014

ótica da centralidade dos processos culturais. Baseado na experiência e na subjetividade humana, que são constituídas pela unidade entre o homem econômico, o homem político e o homem estético, podemos superar "uma visão dicotômica, ainda predominante entre inúmeros educadores, de uma educação escolar para o trabalho e uma educação para a vida" (MARTINS, NEVES, 2013, p. 357).

No entanto, a educação passou a ser vista como um instrumento de mobilidade social, que qualifica o trabalhador para a obtenção do seu emprego, em vez de formá-lo para a vida social. Sendo assim, é atribuído ao trabalhador, e não à crise do capital, a causa de seu desemprego. Em se tratando de EJA, percebemos a presença consistente dessa concepção, pautada em números, estatísticas, índices de desenvolvimento e transferência de recursos públicos para instituições privadas voltadas à qualificação da força de trabalho. Cada vez mais, percebemos a dualidade na educação, já explícita por Gramsci no início do século XX como um apartheid educacional, quando da existência de escolas profissionalizantes para as massas trabalhadoras e escolas humanísticas clássicas para as várias frações da classe dominante.

A escola unitária deveria ser necessariamente uma escola criadora que ensinasse ao conjunto das massas trabalhadoras a pensar, a estudar, a dirigir e a controlar quem dirige. $\mathrm{O}$ advento da escola unitária significaria o início de novas relações entre trabalho intelectual e trabalho industrial não apenas na escola, mas em toda vida social. (GRAMSCI, 2000a, p. 40).

Sob o ponto de vista da educação de classe, a EJA trabalhadores preconiza que, na produção social de sua existência, os seres humanos criam seus próprios valores, sua cultura própria, intrínsecos ao seu modo de vida. Dessa forma, torna-se necessária a resistência às determinações do mercado e à pedagogia política do capital para que as experiências de classe sejam compartilhadas e para que o público da EJA seja conhecedor de sua própria cul - 


\section{Trabalhonecessário}

ISSN: 1808 - 799X

ANO 12, № 19 - 2014

tura, como sujeitos históricos reconhecidos entre si. Em Peculiaridades de E. $P$. Thompson, Negro, Fortes e Fontes comentam a metodologia - de certa forma "radical" para a época - utilizada pelo grupo docente na educação de adultos na Workers Educational Association:

Já o pequeno grupo de Thompson propugnava uma relação entre professor e aluno pouco afeita aos rígidos padrões vigentes. O grupo queria, antes de mais nada, romper a relação entre professor-expositor e audiência passivo-receptora, advogando que a experiência trazida para dentro das salas de aula pela "gente comum" era um poderoso recurso didático, no qual os alunos não deviam enxergar motivos de vergonha ou de autodesmerecimento. (FORTES NEGRO \& FONTES, 2001, p. 26).

A dialética necessária entre educação e experiência, construída por Thompson em sua prática na educação de adultos trabalhadores, "parte do pressuposto de que aquilo que as pessoas comuns fazem é digno de interesse e atenção" (MARTINS, NEVES, 2013, p. 355). Esse princípio, portanto, o aproxima da teoria de Paulo Freire (círculos de cultura) e a de Raymond Williams (o caráter ordinário da cultura e a necessidade da construção de uma cultura em comum). Essa dialética é exposta quando nos referimos à prática docente em EJA trabalhadores:

Toda educação que faz jus a esse nome envolve a relação de mutualidade, uma dialética, e nenhum educador que se preze pensa no material a seu dispor como uma turma de passivos recipientes de educação. (...) $\mathrm{Na}$ educação liberal de adultos, nenhum mestre provavelmente sobreviverá a uma aula - e nenhuma turma provavelmente continuará no curso com ele - se ele pensar, erradamente, que a turma desempenha um papel passivo. (THOMPSON, 2002, p. 13).

A história social como campo historiográfico encontra na obra de Thompson um vasto conjunto de possibilidades. Arcabouço teórico-metodológico para a pesquisa sobre a cultura e o trabalho, desde os meados da década de oitenta ela vem se desenvolvendo no Brasil. Todavia, quando se trata de história da educação feita sob referência thompsoniana, percebemos que há um elo a ser 


\section{Trabalhonecessário}

ISSN: 1808 - 799X

ANO 12, № 19 - 2014

construído. Há a necessidade da ampliação do diálogo com a história social da cultura e do trabalho, com vistas ao amplo estudo das fontes e à análise da agência humana ao longo do tempo à luz da história social da educação. Para Schueler e Mac Cord,

Precisamos viabilizar a aproximação dos historiadores da educação de influência thompsoniana daqueles que labutam na história social brasileira da cultura e do trabalho. Apesar de os primeiros possuírem uma interessante agenda de pesquisa, falta-lhes uma proposta metodológica mais elaborada para selecionar, organizar, cotejar e analisar as fontes. Não basta apenas enunciar que os processos judiciais e as leis educacionais são documentos relevantes. É preciso definir suas limitações e possibilidades analíticas, de acordo com os problemas que conduzirão cada projeto de pesquisa. (SCHUELER \& MAC CORD, 2013, p. 18).

Recapitulando a epígrafe do texto e as experiências dos processos de industrialização ocorridos ao longo da história - principalmente aqueles ocorridos na periferia do capital - percebemos que o avanço das forças produtivas atua em prol da instauração e manutenção de um consenso, e a escola pública possui um papel primordial naquilo que diz respeito à luta contra-hegemônica.

O empobrecimento advindo da Revolução Industrial repercutiu nas péssimas condições de moradia, na inserção das crianças no trabalho fabril, nas longas jornadas de trabalho, no mau cheiro do lixo industrial e deterioração do ambiente urbano. (VENDRAMINI, TIRIBA, 2011, p. 7).

Como na experiência inglesa, é necessária a problematização dos processos de industrialização, os quais são associados ao "progresso" pelo senso comum. Contudo, a luta da classe trabalhadora inglesa e a sua constante formação - haja vista o reconhecimento da educação como pré-requisito para a organização da classe trabalhadora - significou avanços significativos, tal qual o movimento cartista deflagrado em meados do século XIX naquele país, analisado por Thompson com magnificência ao término do terceiro volume de $A$ formação. 


\section{Trabalhonecessário}

ISSN: 1808 - 799X

ANO 12, № 19 - 2014

\section{Referências}

CANARIO, Rui. Educação de adultos. Lisboa: Educa, 2000.

CIAVATTA, Maria; RUMMERT, Sonia Maria. As implicações políticas e pedagógicas do currículo na educação de jovens e adultos integrada à formação profissional. Educ. Soc., Campinas, v. 31, n. 111, p. 461-480, abr.-jun. 2010.

FERREIRA, Marieta de Moraes. História, tempo presente e história oral. Topoi: Rio de Janeiro, dezembro 2002, p. 314-332.

FREIRE, Paulo. Pedagogia do Oprimido. Rio de Janeiro: Paz e Terra, 1985.

FRIGOTTO, Gaudêncio. Juventude, trabalho e educação: o presente e o futuro interditados em suspenso. In: TIRIBA, Lia e CIAVATTA, Maria (Org.). Trabalho e educação de jovens e adultos. Brasília: Liber Livro e Editora UFF, 2011.

GRAMSCI, Antonio. Os intelectuais e a organização da cultura. 4a ed. Rio de Janeiro: Civilização Brasileira, 1982.

GRAMSCI, Antonio. Cadernos do cárcere. v. 2. Rio de Janeiro: Civilização Brasileira, 2000a.

GRAMSCI, Antonio. Concepção dialética da história. Rio de Janeiro: Civilização Brasileira, 1987.

HUTTON, Patrick. History as an art of memory. University Press of New England: 1993.

MARTINS, Angela Maria Souza; NEVES, Lucia Maria Wanderley. Materialismo histórico, cultura e educação: Gramsci, Thompson e Williams. HistedBr online, Campinas, № 51, p. 341-359, jun. 2013.

MARX, Karl. A ideologia alemã. São Paulo: Martins Fontes, 2001.

MATTOS, Marcelo Badaró. E P. Thompson e a tradição de crítica ativa do materialismo histórico. Rio de Janeiro: Editora UFRJ, 2012.

MÉSZÁROS, István. Educação para além do capital. São Paulo: Boitempo, 2002.

SAVIANI, Dermeval. Trabalho e educação: fundamentos ontológicos e históricos.

Revista Brasileira de Educação. V. 12 n. 34 jan./abr. 2007. PP. 152 - 180.

RUMMERT, Sonia Maria. Educação de jovens e adultos trabalhadores e a produção social da existência. In: TIRIBA, Lia e CIAVATTA, Maria (Orgs.).

Trabalho e educação de jovens e adultos. Brasília: Liber Livro e Editora UFF, 2011.

SCHUELER, Alessandra; MAC CORD, Marcelo. História social e história da educação: as contribuições de Edward Thompson. Mimeo, 2013.

THOMPSON, E. P. A miséria da teoria ou um planetário de erros: uma crítica ao pensamento de Althusser. Rio de Janeiro: Zahar, 1981.

THOMPSON, E. P. As peculiaridades dos ingleses e outros artigos. NEGRO, Antonio Luigi \& SILVA, Sergio (org.). Campinas, São Paulo: Editora da Unicamp, 2001.

THOMPSON, E. P. Os Românticos. Rio de Janeiro: Civilização Brasileira, 2002. 


\section{Trabalhonecessário}

ISSN: 1808 - 799X

ANO 12, № 19 - 2014

THOMPSON, E. P. Senhores e caçadores. Rio de Janeiro: Paz e Terra, 1987.

VENDRAMINI, Célia Regina; TIRIBA, Lia. Classe, cultura e experiência na obra de E. P. Thompson: contribuições para a pesquisa em educação. Natal: 34

Reunião anual da Associação Nacional de Pesquisa e Pós-Graduação em

Educação - ANPEd, 2011.

VENTURA, Jaqueline. A trajetória histórica da educação de jovens e adultos trabalhadores. In: TIRIBA, Lia e CIAVATTA, Maria (Orgs.). Trabalho e educação de jovens e adultos. Brasília: Liber Livro e Editora UFF, 2011.

WILLIAMS, Raymond. Marxismo e literatura. Rio de Janeiro, Zahar, 1979.

WILLIAMS, Raymond. Cultura e materialismo. São Paulo, Unesp, 2011, p. 43-68.

Recebido em: 11/09/2014

Aprovado em: 30/10/2014 